\title{
A MINERAÇÃO BRASILEIRA À LUZ DOS OBJETIVOS DE DESENVOLVIMENTO SUSTENTÁVEL
}

\author{
Gabriela Dias de Oliveira, Fábio Ferreira Morong
}

Universidade do Oeste Paulista - UNOESTE, Presidente Prudente, SP. E-mail: gaby.dias.oliveira@hotmail.com

\begin{abstract}
RESUMO
O presente artigo tem por escopo abordar o modo como o progresso e a sustentabilidade tentam atuar de forma unitária pelo desenvolvimento sustentável, de maneira a apresentar brevemente definições acerca dos Objetivos de Desenvolvimento Sustentável (ODS). Além disso, demonstra uma compreensão ampliada de como os ODS e as atividades de mineração brasileira se inter-relacionam de forma harmônica, e além de explanar sucintamente sobre seus efeitos negativos, tenta evidenciar as contribuições potenciais e reais do setor de mineração na concretização dos Objetivos de Desenvolvimento Sustentável. O trabalho, também observa o cumprimento de sua efetiva implementação no território brasileiro e no mundo, bem como os aspectos relacionados à segurança de barragens, evidenciando, como a fiscalização neste contexto, pode ser considerada elemento peculiar primordial, influenciador e adequado aos ODS, e quais medidas podem, eventualmente, ser propostas para alcançar essa essencial harmonia entre ODS e Mineração. $O$ método aplicado foi o dedutivo legal, a partir da análise da legislação nacional e doutrinas. Conclui-se, que é patente a necessidade de inter-relação e harmonia de medidas sustentáveis ligadas à mineração, alterando os métodos como as empresas consomem os recursos minerais, adotando práticas sustentáveis de forma a tornar a extração do minério uma atividade menos agressiva ao meio ambiente, utilizando-se de todas as tecnologias e estudos disponíveis para a minimização e compensação dos impactos gerados, investimentos econômicos para fins sociais e educacionais, sendo, portanto, os ODS da ONU, balizas imprescindíveis para se chegar ao tão esperado desenvolvimento sustentável em âmbito das atividades minerárias no Brasil e no mundo.
\end{abstract}

Palavras-chave: Mineração. Objetivos de Desenvolvimento Sustentável. Segurança de Barragens. Fiscalização.

\section{THE BRAZILIAN MINING ACCORDING TO THE OBJECTIVES OF MAINTAINABLE DEVELOPMENT}

\begin{abstract}
This article has the scope of the way the process and the sustainability try to act in a united form for the sustainabe development, in a way to briefly present definitions towards the sustainable development goals (SDG). Futhermore, it demonstraits a wide comprehention of how the SDG and the brazilian mining activities interrelate harmonicly, besides explaining completly its negative effects, it trys to show the real contribution and potential of the mining sector in the sustainable development goals. This paper also observes the fulfillment of its effective implementation in the brazilian territory and in the world, as well as aspects related to the dam safaty, showing, how the how the fiscalization in this context, can be considered the primary element, influent and adpted to the SDG, and whatever way may be, enventually, be propost to reach this essential harmony between SDG and Mining. The mathod applied was the legal deductive, from this analysis of the national lesgisation and doctrine. Therefore it is pertinent the need of interrelate and harmony of sustainable methods conected to mining, changing how the companies use the mining resorces, changing it to sustainable actions in a way that makes the extrations of ores a less agressive activitie to the enviorment, using of all the tecnology and studies available to minimize and compreheend the impacts generated, economic investiments to social and educational purposes, thus being ONU's SDG,
\end{abstract}


indispensables way to reach the higly expected sustainable development in the mining activies areas of Brazil and the world.

Keywords: Mining. Sustainable development goals. Dam safaty. Inspection.

\section{INTRODUÇÃO}

A humanidade, em sua incansável e interminável busca pelo progresso, utiliza-se de todos os meio disponíveis, dentre esses se encontram os recursos naturas, para atingir esse avanço. Entretanto, tais recursos não são em geral renováveis, de modo a serem finitos e, portanto, passíveis de uma maior atenção e respeito ao serem utilizados, devendo ter como objetivo a busca por um desenvolvimento sustentável.

Os 17 Objetivos de Desenvolvimento Sustentável (ODS), foram criados pelos líderes da Organização das Nações Unidas (ONU, 2015), buscando alcançar o, até então utópico, mundo sustentável. A mineração, se em consonância aos Objetivos de Desenvolvimento Sustentável, pode gerar empregos dignos, crescimento econômico, inovação, investimentos em infraestrutura, além da diminuição das desigualdades sociais. Contudo, caso em desacordo com tais objetivos, pode gerar desastres ambientais, aumento das desigualdades sociais, além de diversos outros conflitos.

Assim, a mineração é um dos polos que deve adotar tais medidas de desenvolvimento sustentável, pois em conformidade aos avanços alcançados no século XXI, e em tangência aos princípios e objetivos sustentáveis estabelecidos pela ONU, uma rápida e eficaz mudança deve ser concretizada, diante dos atuais desastres provocados por rompimento de barragens no campo da mineração.

O trabalho busca demonstrar uma compreensão ampliada de como os Objetivos de Desenvolvimento Sustentável (ODS) e a mineração brasileira se inter-relacionam, observando o aspecto de incentivo de sua efetiva implantação no território brasileiro e no mundo, bem como alguns dos aspectos de cunho negativo e ainda, relacionados à segurança de barragens e fiscalização.

\section{METODOLOGIA}

O método aplicado neste trabalho é o método dedutivo, que parte de uma generalização para uma questão particularizada.
Segundo Gil (2008), este método de pesquisa parte de princípios reconhecidos como verdadeiros e indiscutíveis e possibilita chegar a conclusões em virtude unicamente de sua lógica. Para elaboração do presente artigo, foram utilizadas as metodologias de pesquisa bibliográfica conceitual por doutrinas, além da análise de jurisprudências, legislações nacionais artigos científicos com pertinência ao tema abordado.

\section{ASPECTOS GERAIS SOBRE OS OBJETIVOS DE DESENVOLVIMENTO SUSTENTÁVEL (ODS)}

Como resultado da reunião de líderes mundiais, realizada na sede da Organização das Nações Unidas (ONU), constituiu-se a famosa Agenda 2030, instrumento por meio da qual se objetivou a deliberação acerca de um conjunto de ações visando alcançar o Desenvolvimento Sustentável (PLATAFORMA AGENDA 2030, 2017).

As deliberações da Agenda 2030, ou Agenda de Desenvolvimento Sustentável Pós2015, foram concluídas em 2015. Aludidas deliberações resultaram nos 17 Objetivos de Desenvolvimento Sustentável (ODS), cuja efetivação ocorre dentre os anos de 2016 a 2030. De sorte, os 17 Objetivos buscam garantir o equilíbrio entre as pessoas e o planeta, a prosperidade e paz. Conta ainda com 169 metas correspondentes (MORONG; ALVES, 2017).

O desenvolvimento sustentável inserido dentre os 17 Objetivos, é almejado em quatro dimensões principais, quais sejam: as de natureza social, que interligam-se à questões de natureza humana, envolvendo educação e melhoria da qualidade de vida; as de natureza econômica, abordando o uso, bem como esgotamento de recursos naturais e envolvendo questões como consumo de energia e produção de resíduos; as de natureza institucionais, que ressaltam às capacidades de colocar em prática os Objetivos e, essencialmente, as de natureza ambiental, que servirão de embasamento para o desenvolvimento deste estudo, que tratam do uso sustentável dos recursos marinhos, implementação de medidas efetivas contra mudanças do clima, bem como a preservação e 
conservação do meio ambiente (ESTRATÉGIA ODS, 2018).

Logo, é certo que os Objetivos de Desenvolvimento Sustentável representam uma estratégia ampla de ações no mundo destinadas à inclusão social, sustentabilidade ambiental e desenvolvimento socioeconômico.

\section{A MINERAÇÃO BRASILEIRA E SUA BREVE RELAÇÃO COM O OBJETIVOS DE DESENVOLVIMENTO SUSTENTÁVEL}

$A$ atividade mineradora de fato, de acordo com Sirvinkas (2018), pode ser definida como o ato de extração de minérios do subsolo, tais como: carvão, petróleo, pedras preciosas, ouro, prata, areia, sílica, mica, quartzo, feldspato, apatita, dolomita, calcita, ferro, manganês, cassiterita, níquel, cobre, zinco, potássio etc., acrescentando ainda que a exploração desses minérios causam impactos negativos significativos ao meio ambiente, especialmente no Brasil, onde o método de extração é ainda muito rudimentar.

No Brasil, o principal diploma legal em matéria infraconstitucional que regulamenta a atividade de extração mineral é o Código de Minas, estabelecido pelo Decreto-lei № 227, de 28 de fevereiro de 1967, com as alterações que Ihe foram introduzidas pela Lei no 7.805 , de 18 de julho de 1989. Este Código, tendo em vista que a propriedade dos recursos minerais independe da propriedade do solo, tem por função básica o regramento da atividade do Poder Público como administrador dos recursos minerais. (ANTUNES, 2017).

Importante ressaltar a instituição do Departamento Nacional de Produção Mineral (DNPM), que consiste em uma autarquia federal, dotada, portanto, de autonomia administrativa e financeira, criada pela Lei 8.876/1994 e pelo Decreto 1.324/1994, e vinculada ao Ministério de Minas e Energia. O DNPM possui a finalidade de promover o planejamento e o fomento da exploração e do aproveitamento dos recursos minerais, e superintender as pesquisas geológicas, minerais e de tecnologia mineral, bem como assegurar, controlar e fiscalizar $o$ exercício das atividades de mineração em todo o território nacional (BELTRÃO, 2014).

Por sua vez, o tema é também, evidentemente, de grande repercussão econômica e ambiental. Ao analisarem a importância do ordenamento jurídico da atividade minerária, Lauro Lacerda Rocha e Carlos
Alberto M. Lacerda (ROCHA; LACERDA, 1983), entendem que a realidade é de maior preponderância econômica, política e estratégica do Estado.

Segundo Enríquez e Drumond (2007, p. 245), é necessário abordar os dilemas da mineração na perspectiva do desenvolvimento sustentável. Afinal, se, de um lado, o setor mineral é imprescindível para a estrutura econômica e social das sociedades contemporâneas, de outro, a atividade impõe um desafio e, ao mesmo tempo, um "duplo compromisso" com as gerações presentes (intrageração) e com as gerações futuras (intergeração)

De outro lado, divergindo do conceito com características degradantes da atividade de mineração, o Programa das Nações Unidas para o Desenvolvimento (PNUD) e o Ministério de Minas e Energia lançaram em Brasília (DF), a versão em português do "Atlas: Mapeando os Objetivos de Desenvolvimento Sustentável na Mineração". O Atlas foi produzido em parceria com o Fórum Econômico Mundial, o Centro de Investimento Sustentável da Universidade de Columbia, a Rede de Soluções para o Desenvolvimento Sustentável e o PNUD, com apoio da Agência Alemã de Cooperação Internacional (GIZ). (CONFEDERAÇÃO NACIONAL DA INDÚSTRIA, 2017).

O documento, que traz contribuições de iniciativas brasileiras, destaca a atuação do setor na Agenda 2030, com informações sobre como as atividades de mineração podem contribuir para cada um dos 17 ODS, de maneira que, servirá como um dos principais fundamentos na elaboração do presente artigo. (MME, 2018)

\section{BREVE ANÁLISE SOBRE O MAPEAMENTO DOS OBJETIVOS DE DESENVOLVIMENTO SUSTENTÁVEL NA MINERAÇÃO}

Com a finalidade de tentar provar ser possível haver uma relação positiva entre a mineração e os ODS, o citado Atlas mapeia a relação entre a mineração e os ODS, aplicando como método, a execução de boas práticas existentes na indústria, de conhecimentos específicos e de recursos no desenvolvimento sustentável. De acordo com seu conteúdo, se tais métodos forem replicados ou ampliados, poderão prover contribuições úteis para o ODS. 2017, p. 4):

Segundo o referido Atlas (COLUMBIA,

A mineração é uma indústria global e está 
frequentemente localizada em áreas remotas, ecologicamente sensíveis e menos desenvolvidas, que incluem diversos territórios, inclusive os indígenas. Quando gerida de forma adequada, pode criar empregos, estimular a inovação e trazer investimentos e infraestrutura em uma escala de mudanças de longo prazo. No entanto, se mal administrada, a mineração pode também levar à degradação do meio ambiente, ao deslocamento de populações, à desigualdade e aumento de conflitos, entre outros desafios.

Partindo deste preceito, o Atlas, por sua vez, apresenta uma visão ampla de oportunidades e desafios, para demonstrar as contribuições potenciais e reais do setor de mineração na realização dos ODS, desde a exploração até a produção e, eventualmente, o encerramento da mina.

Dentre os impactos positivos que a mineração eventualmente pode acarretar, o aludido documento busca demonstrar o papel que as empresas de mineração podem desempenhar na realização de todos os 17 ODS, tendo em conta os impactos positivos e negativos da mineração, combinados com a capacidade da indústria para mobilizar recursos humanos físicos, tecnológicos e financeiros. (CONFEDERAÇÃO NACIONAL DA INDÚSTRIA, 2017, p. 53-55).

Com efeito, resta evidente que tal documento, produzido em parceria com o Fórum Econômico Mundial, o Centro de Investimento Sustentável da Universidade de Columbia, a Rede de Soluções para o Desenvolvimento Sustentável e o PNUD, com apoio da Agência Alemã de Cooperação Internacional (GIZ), tem como finalidades, de forma geral, incentivar as empresas de mineração de todos os portes a incorporar os ODS relevantes em seus negócios e operações, validar os seus esforços atuais e estimular novas ideias (MME, 2017).

De forma mais específica, as diretrizes apontadas buscam alcançar os governos nacionais, em todos os ministérios relevantes das áreas de mineração, bem como governos locais, comunidades, agências de desenvolvimento e organizações da sociedade civil, para apoiar os programas e esforços e ajudar a desbloquear o potencial do setor de mineração, de modo a contribuir para um futuro sustentável e servir de estímulo para um diálogo mais inclusivo e de cooperação.

Além disso, almeja ser útil aos Fóruns e grupos de diálogo existentes em âmbito local da mineração e no âmbito do país, e também às universidades e instituições de aprendizagem como uma fonte de ideias e oportunidades para convocar e coordenar a educação, pesquisa e desenvolvimento profissional que possa lidar com a mineração e os ODS. (COLUMBIA, 2017).

Denota-se, que o escopo principal é de constituir um elo entre $o$ desenvolvimento sustentável e a mineração, o que de fato, realmente é uma tarefa desafiadora, sobretudo, quando os impactos negativos sobrepõem-se aos positivos.

\section{DA INTER-RELAÇÃO DA MINERAÇÃO COM OS OBJETIVOS DE SUSTENTÁVEL (ODS) DESENVOLVIMENTO}

Como já observado anteriormente, o documento internacional analisa a relação entre as atividades de mineração e os 17 ODS, com modelos de ações concretas, as quais se confiam que sejam ampliadas ou expandidas.

No tocante aos objetivos do Atlas em estudo (COLUMBIA, 2017, p. 04):

Ao mapear as ligações entre mineração e os ODS, o objetivo deste Atlas é incentivar as empresas de mineração de todos os portes a incorporar os ODS relevantes em seus negócios e operações, validar os seus esforços atuais e estimular novas ideias. O sucesso também vai exigir parceria substancial e permanente entre os governos, o setor privado, as comunidades e a sociedade civil, e esperamos que o Atlas estimule ações que irão alavancar o poder transformador da colaboração e parceria entre a indústria de 
mineração e outras partes interessadas.

Desta feita, o esboço indica que a indústria de mineração tem a oportunidade e potencial para contribuir de forma positiva para todos os 17 ODS, ampliando a compreensão de como os ODS e a mineração se inter-relacionam.

Salienta-se ainda que, os desígnios e metas devem ser cumpridos por todos os povos e segmentos da sociedade, incluindo os mais vulneráveis. Por isso, o cumprimento dos ODS em 2030, demandará uma cooperação intensa e a cooperação entre os governos, as organizações não governamentais, o setor privado $\mathrm{e}$ as comunidades. (CUNH; , GUEDES, 2017)

Pois bem, em que pese possam existir divergências em decorrência de critérios utilizados em razão dos impactos positivos e negativos da mineração, essa indústria tem a oportunidade e potencial para colaborar de maneira positiva para todos os 17 ODS.

Para melhor esclarecer, Cunha e Guedes (2017) explanam o tema dos impactos negativos e positivos, citando incialmente, como impactos positivos, por exemplo, avanços significativos promovidos pela indústria mineral no sentido de ampliar as externalidades positivas, dentre elas o desenvolvimento econômico, lembrando que inúmeros minerais produzidos pela indústria de mineração também são peças essenciais para tecnologias, infraestrutura, energia e agricultura.

Já no que tange aos impactos negativos, no Atlas, também é realizada referência aos impactos que, historicamente, estão relacionados à atividade mineral, como os desequilíbrios ambientais, o deslocamento de populações, agravando a desigualdade econômica e social, os conflitos armados, violência baseada em gênero, evasão fiscal e corrupção, além dos problemas de saúde.

Por conseguinte, é certo que o Atlas evidencia a função que as empresas de mineração podem exercer na concretização de todos os 17 ODS, tendo em conta os impactos positivos e negativos da mineração, combinados com a capacidade da indústria para mobilizar recursos humanos, físicos, tecnológicos e financeiros.

\section{DA CORRELAÇÃO ENTRE OS ODS 01, ODS 08, ODS 09 E ODS 17}

Em relação ao ODS 01, o relatório destaca que a atividade mineral pode contribuir para 0 alcance da erradicação da pobreza, porque inclui acesso a oportunidades, saúde, bens e serviços e, principalmente, a condições mínimas de sobrevivência. Essas incluem, por exemplo, a ampliação da produtividade agrícola, que depende fundamentalmente da atividade de mineração. (ALMEIDA et al., 2019)

Além disso, o pagamento de impostos e royalties permite o desenvolvimento de bens públicos básicos, como o acesso à saúde, habitação, educação e infraestrutura, fazendo com que a mineração também possa ajudar a reduzir a pobreza por meio de: criação de emprego, atividade econômica induzida, prestação de serviços básicos e desenvolvendo estratégias eficazes para restabelecer os meios de subsistência que podem ser negativamente afetados por suas operações, incluindo a garantia de acesso a terra e aos recursos naturais para as pessoas de comunidades mineiras. (PNUD, 2017).

No que diz respeito ao ODS 8, "Trabalho decente e crescimento econômico", as mineradoras têm o potencial, por meio de ações que gerem empregos, políticas públicas e privadas que impulsionem investimentos e que requeiram um olhar novo, com vistas em aumentar a produtividade; diversificação de mercados e oportunidades; e melhoria da criatividade e da inovação. Combinando um foco na eliminação do trabalho infantil e um de proteção dos direitos trabalhistas, o ODS8 visa promover o crescimento econômico com oportunidades de trabalho digno para todos. (UNITED NATIONS, 2016).

Apesar das expectativas, o emprego direto gerado pela mineração em grande escala pode ser limitado. No entanto, ele tem o potencial de grande multiplicador econômico por meio das aquisições locais. As empresas de mineração, em parceria com outras partes interessadas, podem ajudar a construir abordagens para promover a concorrência das empresas nacionais, para aumentar o conteúdo e fornecimento de capacidades locais, o que também traz uma unidade mais sustentável, de longo prazo, e o crescimento econômico diversificado. (PNUD, 2017).

De acordo com o Conselho Internacional de Mineração e Metais (ICMM), um funcionário de uma empresa pode corresponder a três ou quatro funcionários de outros setores da economia, pois, devido à oferta de trabalho, há um aumento da demanda local para atender as necessidades induzidas pela mina. As empresas 
de mineração podem rever e documentar as diferentes formas de contribuir para o crescimento econômico, e essa linha de pesquisa pode servir como modelo para a identificação de oportunidades para alavancar o crescimento mais inclusivo e sustentável. (ICMM, 2012).

Para o alcance do ODS 9, "Indústria, inovação e infraestruturas", as mineradoras podem estimular $o$ desenvolvimento e a diversificação econômica, com estímulos e construção de novas infraestruturas de água, energia, transportes e comunicações. Transportes, água, energia e infraestrutura para tecnologia da informação e comunicação (TIC), são necessários para o desenvolvimento sustentável. Esses serviços básicos são essenciais para as sociedades dinâmicas e resilientes, para sistemas de saúde e educacionais robustos que funcionem adequadamente, e para a produtividade agrícola e econômica. (UNITED NATIONS, 2016).

Dessa forma, o uso compartilhado de infraestrutura, especialmente em países com um déficit de financiamento em infraestrutura de grande porte, representa uma oportunidade significativa para a mineração expandir o acesso a serviços essenciais. Dadas as características geológicas distintas que exigem técnicas de mineração especializadas, as empresas de mineração também podem contribuir para a inovação no país com programas de pesquisa e desenvolvimento e por meio de suas práticas de aquisições. (PNUD, 2017).

Logo, é certo que as empresas de mineração podem ter um papel ativo na promoção da indústria nacional, eis que, as mesmas práticas que podem ser usadas para reduzir a pobreza e promover emprego gerando crescimento econômico, também podem orientar a industrialização no sentido de buscar o desenvolvimento sustentável. (PNUD, 2017).

Com vistas à abrangência do ODS 17 , "Parcerias para a implementação dos ODS", avançar na agenda do desenvolvimento sustentável requer parcerias substanciais e contínuas entre os governos, o setor privado e a sociedade civil. Nesse sentido, a ONU solicita ação urgente e imediata, para mobilizar o poder transformador de recursos privados para cumprir os ODS. Investimentos de longo prazo por parte dos setores público e privado, são necessários em áreas críticas, como a energia sustentável, infraestrutura, transporte e tecnologias de informação e comunicação. $O$ setor público precisa definir parâmetros claros para esses investimentos e fornecer os quadros de monitorização, regulamentos e estruturas de incentivo necessários para alavancar resultados sustentáveis. (UNITED NATIONS, 2016).

Portanto, pode-se concluir que a mineração torna-se cada vez mais uma aliada ao desenvolvimento sustentável, convergindo objetivos como o trabalho decente à erradicação da pobreza, tendo como consequência o crescimento econômico e trazendo inovação no quesito das indústrias e infraestrutura de modo geral. No entanto, para isso torna-se realidade, é necessário o apoio de parcerias para a implementação desses ODS.

\section{DA COMPATIBILIDADE ENTRE OS ODS 03, ODS 06 E ODS 07}

A respeito do ODS n 03, "Saúde e bemestar", assegurar uma vida saudável e promover o bem estar em todas as idades é essencial para o desenvolvimento sustentável. Avanços significativos foram realizados, no que diz respeito ao aumento da expectativa de vida e na redução de algumas das causas mais comuns de mortalidade infantil e materna. Grandes progressos foram criados para aumentar o acesso à água potável e saneamento, ajudando assim a reduzir a malária, a tuberculose, poliomielite e a propagação do HIV / AIDS. No entanto, são necessários mais esforços para erradicar totalmente uma ampla gama de doenças, e resolver muitos problemas de saúde persistentes e emergentes. O ODS 03 se concentra na saúde infantil, saúde materna, HIV /AIDS, na malária e em outras doenças evitáveis e crônicas (UNITED NATIONS, 2016).

Por sua vez, as empresas de mineração podem, por meio de investimentos econômicos, capacitação e atividades socioambientais, em parceria com comunidades, governo e outras partes interessadas, melhorar a acessibilidade aos serviços de saúde, a qualidade dos cuidados com a saúde e abordagens conjuntas de monitorização, bem como dar resposta às epidemias de saúde. Essas empresas podem impulsionar o seu compromisso com a saúde e segurança, e sua experiência interna para beneficiar a saúde da comunidade, colaborando para fortalecer os serviços de saúde e combatem doenças infecciosas. (PNUD, 2017).

No tocante ao ODS 06, "Água potável e saneamento", é plausível a constatação de que a falta de saneamento, de higiene e de 
infraestrutura adequada contribuem para doenças e milhões de mortes por ano. $\mathrm{O}$ acesso à água potável e aos serviços de saneamento de qualidade previnem doenças e evoluem os meios de subsistência, as águas navegáveis limpas, mantendo um meio ambiente saudável. (UNITED NATIONS, 2016).

A mineração utiliza significativa quantidade de água e pode impactar negativamente a sua qualidade. A indústria de mineração pode contribuir para o acesso adequado à água potável e ao saneamento, reduzindo a sua própria pegada de carbono em quantidade e qualidade, com medidas de eficiência e a reciclagem da água. Da mesma forma, com o aumento da oferta local de água por meio da infraestrutura hídrica e de uso compartilhado, obtido com fontes hídricas apropriadas, garantindo que as suas operações não desloquem usuários locais ou poluam o abastecimento, e afetem o compartilhamento de dados no monitoramento da água com os governos locais (PNUD, 2017).

Acerca do ODS 07, "Energia limpa e acessível", segundo dados do Ministério de Minas e Energia e o PNUD (2017), constata-se que uma em cada cinco pessoas não têm acesso à eletricidade, e 3 bilhões de pessoas utilizam madeira, carvão vegetal ou dejetos animais para cozimento e aquecimento. Este ODS é um componente crítico e também é um facilitador do desenvolvimento sustentável em muitos dos outros objetivos.

É certo que a mineração é uma atividade de consumo intenso de energia, mas que pode melhorar a sustentabilidade energética, acelerando a incorporação de medidas de eficiência energética e de energias renováveis em suas fontes de alimentação das minas. Embora a eficiência energética seja um foco necessário, a mineração também pode alavancar sua demanda elétrica para prolongar a energia em áreas escassas de suprimentos, por meio de parcerias que permitam a utilização partilhada da infraestrutura energética (PNUD, 2017).

Destarte, conclui-se que há uma extrema compatibilidade entre saúde e bem-estar, água potável e saneamento e energia limpa e acessível, pois todos congruem para uma mesma direção, sendo esta a melhoria da vida da população. Para tanto, a mineração pode ser uma grande colaboradora para que tais objetivos sejam alcançados, já que pode aliar desenvolvimento e sustentabilidade por meio das ações e medidas explanadas.

\section{DA PARIDADE ENTRE OS ODS 02, ODS 11 E ODS} 12

No que se refere ao ODS 02, "Fome zero e agricultura sustentável", busca-se acabar com a fome, melhorando a sustentabilidade dos sistemas alimentares e agrícolas globais. Isto significa reduzir os impactos negativos sobre o planeta em solos, água doce, oceanos, pesca, florestas e biodiversidade. O ODS 02, aborda principalmente, a produção agrícola e sua contribuição para a erradicação da fome e da pobreza. A agricultura é o maior empregador do mundo, e o meio de subsistência primário para as famílias rurais pobres (UNITED NATIONS, 2016).

No que tange ao ODS 11, "Cidades e comunidades sustentáveis", compreende-se que metade da população mundial vive hoje nas cidades. Até $2030,60 \%$ da humanidade vão ter suas casas em cidades. (UNITED NATIONS, 2016). Por sua vez, as empresas de mineração podem contribuir com as cidades e comunidades sustentáveis, apoiando o desenvolvimento de infraestruturas locais relevantes, envolvendo todas as partes interessadas no planejamento e no uso da terra, na implementação de planos de patrimônios culturais, e na recuperação de terrenos em parques e espaços verdes, onde couber. Aterros de mineração para reduzir o desperdício e aumentar a reutilização de materiais e tecnologias, são também potenciais contribuições (PNUD, 2017).

As empresas de mineração podem adotar o planejamento de vida útil da mina a partir do desenvolvimento de estratégias de uso da terra e de infraestrutura. Isso inclui considerar o uso da terra pós-encerramento, no planejamento de estratégias para tal, e alinhar qualquer expansão da pegada de carbono com uso antecipado pela comunidade. Isso também inclui, analisar formas de minimizar a pegada de carbono da mina e a construção de abordagens operacionais, para reduzir o custo e o impacto de encerramento na concepção inicial do projeto (THE CITIES ALLIANCE, 2008).

Em referência ao ODS 12, "Produção e consumo sustentáveis", a ONU estima que um terço de todos os alimentos produzidos anualmente - o equivalente a 1,3 bilhões de toneladas no valor de cerca 1 trilhão de dólares acaba apodrecendo em caixotes de lixo, ou estragam-se durante $\mathrm{o}$ processo de colheita e transporte para o mercado (UNITED NATIONS, 2016). 
Todavia, o processo de mineração produz materiais úteis para a sociedade, que estão presentes em produtos usados no dia a dia. De outro lado, a mineração também gera resíduos, em grande parte inutilizáveis, o que demanda certos cuidados e estratégias no que diz respeito a gestão de resíduos. Denota-se que, apesar desses desafios, a mineração pode contribuir para uma produção mais sustentável, por meio uma gestão de produção e resíduos coerente com a situação do entorno e da região (ICMM, 2006).

Para tanto, as empresas podem colaborar com os governos em toda a cadeia de abastecimento para apoiar uma economia circular, minimizando entradas de resíduos no processo de mineração, de modo que, passam a aumentar a reutilização, reciclagem e o reaproveitamento de matérias-primas, e produtos para melhorar o consumo sustentável. (PNUD, 2017)

Por conseguinte, pode-se chegar à premissa de que os objetivos que buscam alcançar a fome zero e sustentabilidade na agricultura, nas cidades e comunidades e também na produção e no consumo, buscam todos um mesmo fim, sendo esse a sustentabilidade como forma de melhorar a vida da população dessa região. Do mesmo modo, a mineração pode ser aproveitada como um meio para que tais fins sejam obtidos, aliando desenvolvimento e sustentabilidade.

\section{DA SIMILITUDE ENTRE OS ODS 04, ODS 05, ODS 10 E ODS 16.}

No que concerne ao ODS 04, "Educação de qualidade", observa-se que as habilidades, os conhecimentos e a aprendizagem adquiridos por meio da educação, são de extrema importância na construção da melhoria da vida das pessoas. Soma-se a isso o fato de que a mineração pode contribuir para uma educação de qualidade, com programas de formação técnica, profissional e de educação para a força de trabalho de mineração atual e no futuro. (COLUMBIA, 2017)

As empresas podem colaborar para garantir que se ofereçam a formação técnica exigida pela indústria de mineração, e também podem investir em escolas e formação de professores, colaborando com o governo e comunidades para melhorar a qualidade $e$ disponibilidade de oportunidades educacionais. Um cuidado especial é exigido onde trabalhadores qualificados não pertençam à comunidade local. Trazer trabalhadores qualificados de outras áreas, sem investir em estratégias de qualificação de trabalhadores locais, poderia marginalizar moradores da comunidade, contribuir para as desigualdades econômicas e educacionais e impactar negativamente a relação comunidade empresa. (PNUD, 2017). Por isso, o investimento local de forma preferencial, dada à peculiaridade do assunto, é medida positiva e necessária.

Para o alcance do ODS 05, "Igualdade de gênero", compreende-se como necessária a definição de tal, como a abrangência da igualdade de acesso para as mulheres e meninas aos cuidados de saúde, educação e emprego, e da igualdade de participação na tomada de decisão política e econômica. A igualdade de gênero é um direito humano fundamental, no entanto, ainda há lacunas significativas existentes nos direitos de mulheres e meninas para participar plenamente nas suas comunidades e sociedades. (UNITED NATIONS, 2016).

Desse modo, as empresas de mineração podem promover a igualdade de gênero, garantindo a sua paridade e a igualdade de remuneração por trabalho comum em todos os níveis da organização. De igual forma, podem implementar esforços proativos para recrutar e manter empregados do sexo feminino, e tornar o ambiente de trabalho um lugar seguro para as mulheres. Em comunidades impactadas pela mineração, as mulheres tendem a ter menos benefícios e estarem sujeitas a impactos mais negativos do que os homens. Isso pode ser resolvido por meio do reconhecimento dos direitos das mulheres a recursos e bens, incluindo-as como partes interessadas nos processos de aquisição de terras, de reinstalação e de consulta, e construção de acesso, inclusive a empregos e oportunidades econômicas. (PNUD, 2017).

Em adição a tais objetivos, encontra-se o ODS 10, "Redução das desigualdades", que traz a perspectiva da existência de disparidades, como por exemplo, algumas populações que ainda não têm acesso à infraestrutura básica e oportunidades econômicas, apesar das melhorias significativas no país em geral. (PNUD, 2017)

Segundo o Altas em estudo (2017), várias nações dependentes da atividade de mineração lutam contra a desigualdade econômica e, existem diversas pesquisas existem para examinar a relação entre as atividades de mineração, a pobreza, igualdade de renda e 
reinvestimento governamental das receitas de mineração, entre outros fatores. A desigualdade econômica cria desigualdade social, levando, às vezes, a conflitos sociais e à deterioração da licença social da empresa de mineração para operar. Assim, o citado documento explana que, enquanto os governos são os principais responsáveis pela redução da desigualdade com políticas e mecanismos de redistribuição, a mineração pode desempenhar um papel ativo pela promoção da inclusão em emprego direto, aproveitando os benefícios econômicos diretos, indiretos e induzidos pelas aquisições locais, e colaborando com os governos e as comunidades para apoiar consultas públicas transparentes, apoiando a diversificação no sustento familiar, e expandir o acesso à infraestrutura e aos serviços básicos. (COLUMBIA, 2017)

No tocante ao ODS 16, "Paz, justiça e instituições eficazes", trata-se da construção de um acesso mais eficaz à justiça, e às instituições que contribuem para a regra transparente de direito e a proteção dos direitos humanos. Assegurar a paz, também significa reduzir a violência e os conflitos, a proteção das crianças, reduzindo a corrupção e ampliando as oportunidades para as pessoas participarem nas decisões e planejamentos de governo (UNITED NATIONS, 2016).

Assim, as empresas de mineração podem auxiliar a fortalecer as instituições responsáveis e transparentes, combatendo ativamente os fluxos financeiros ilícitos relacionados à mineração, por meio de divulgação da informação. Também, pode contribuir para sociedades pacíficas ao remediar conflitos no âmbito da empresacomunidade, proporcionando acesso à informação, respeitando os direitos humanos, apoiando representantes nas tomadas de decisão, e gerindo cuidadosamente as suas abordagens de segurança, para garantir que diminuam a probabilidade de conflito, ao invés de aumentá-la. Ademais, as empresas de mineração, podem se comprometer com a transparência no âmbito das atividades que impactam a sociedade, sendo proveniente das receitas aos pagamentos de compromissos assumidos com as comunidades locais. (PNUD, 2017).

Isto posto, conclui-se que a educação de qualidade, aliada a paz, justiça e instituições eficazes, promovem a igualdade de gênero, reduzindo, deste modo, as desigualdades como um todo na sociedade, desde de econômicas às sociais. Ademais, mostrou-se a mineração ser uma aliada a tais objetivos, no momento em que pode investir no crescimento social da comunidade onde instalada, trazendo benefícios mútuos e gerando um desenvolvimento sustentável para todos.

\section{DA CONFLUÊNCIA ENTRE OS ODS 13, ODS 14 E ODS 15.}

No que se refere ao ODS 13, "Ação contra a mudança global do clima", apura-se que nas próximas décadas, a mudança climática está assinalada para obstruir as economias nacionais e afetar adversamente os meios de vida das pessoas, por meio da mudança de padrões climáticos, o aumento do nível do mar e eventos climáticos mais extremos. (UNITED NATIONS, 2016). Assim, as empresas de mineração, podem colaborar ao combate das alterações climáticas, reduzindo a sua pegada de carbono e também, por meio do diálogo com as partes interessadas para melhorar a capacidade de adaptação, e integrar medidas relativas às alterações climáticas nas políticas e estratégias. Por isso, como metas-chave do ODS 13 da ONU relevantes para a atividade de mineração, estão previstos o reforço à resiliência e a capacidade de adaptação a riscos relacionados ao clima e às catástrofes naturais em todos os países; a melhora na educação, aumentando a conscientização e a capacidade humana e institucional sobre mitigação, adaptação, redução de impacto e alerta precoce da mudança do clima; além de promover mecanismos para a criação de capacidades para o planejamento relacionado à mudança do clima e à gestão eficaz, nos países menos desenvolvidos, inclusive com foco em jovens, mulheres, comunidades locais e marginalizadas. (COLUMBIA, 2017).

Com relação ao ODS 14, "Vida Aquática", tal objetivo, trata da redução dos impactos negativos sobre os oceanos do mundo e a proteção de ecossistemas marinhos frágeis.

É certo que a mineração impacta o oceano de várias maneiras, seja por meio do uso dos mares para o transporte de produtos, da mineração rasa, dos rejeitos submarinos, das populações ribeirinhas e da nova fronteira da mineração em alto-mar. De outro lado, as empresas de mineração podem contribuir para a sustentabilidade dos oceanos por meio da identificação de impactos relacionadas com o mar, compreendendo a dependência das comunidades locais em relação aos recursos 
marinhos e engajando-se na proteção e conservação dos oceanos e mares. Ademais, podem aumentar os benefícios econômicos para os pequenos Estados insulares em desenvolvimento, e os países menos desenvolvidos, a partir do uso sustentável dos recursos marinhos, inclusive por meio do turismo e de uma gestão sustentável da pesca e aquicultura. (PNUD, 2017).

No que concerne ao ODS 15, "Proteção à vida terrestre", apura-se que a atividade de mineração e sua infraestrutura associada, podem perturbar tanto os ecossistemas que prestam serviços valiosos, quanto a sociedade e a biodiversidade de que esses ecossistemas dependem. O setor de mineração também se configura como importante gestor de terras, como por exemplo, no arrendamento de locais para a mineração, que geralmente causam impacto maior em sua pegada de carbono. Como gestores de terras, as empresas de mineração têm um papel importante a desempenhar na biodiversidade e gestão da conservação. (CROSSSECTOR BIODIVERSITY INITIATIVE, 2015).

Dessa forma, projetos podem ser gerados pela indústria da mineração, de modo a evitar ou minimizar os impactos negativos em espécies, criando pesquisas sobre o risco de espécies em extinção durante a atividade de exploração, programas de conservação, proteção de espécies ameaçadas ou em perigo de extinção, eliminação de espécies invasoras, restauração de ecossistemas deslocados ou interrompidos, e o uso de compensações de biodiversidade para tratar impactos residuais. (PNUD, 2017).

Portanto, pode-se concluir que, desde pelos menores atos realizados por qualquer cidadão ou a atividade mineradora como um todo, o mundo pode sofrer consequências, podendo essas também serem positivas, caso haja uma mudança geral na gestão das atividades mineradoras em relação à política de câmbio climático, impedindo o aumento da mudança global do clima, e assim, tentar melhorar de maneira considerável essa questão mundial, desde a vida terrestre à vida aquática, promovendo, desta forma, o desenvolvimento sustentável harmônico com a referida atividade.

\section{DA FISCALIZAÇÃO COMO PONTO PROEMINENTE PARA A CONSECUÇÃO DO DESENVOLVIMENTO SUSTENTÁVEL NA MINERAÇÃO}

Por sua vez, é certo que uma maior fiscalização governamental das atividades minerárias e dos mercados globais voláteis, também apontam para uma maior relevância das dimensões da sustentabilidade de relações governamentais. (CONFEDERAÇÃO NACIONAL DA INDÚSTRIA, 2017, p. 63).

Em 2010, a Lei Federal no 12.334/2010, estabeleceu a Política Nacional de Segurança de Barragens (PNSB), sendo uma norma específica para a fiscalização, monitoramento e verificação da segurança de barragens destinadas à acumulação de água para quaisquer usos, à disposição final ou temporária de rejeitos e à acumulação de determinados resíduos industriais. (SIRVINKAS, 2018).

Segundo Paulo Affonso Lemes Machado (2013, p. 592-593):

Segurança de barragem e a condição que visa a manter a sua integridade estrutural e operacional e a preservação da vida, da saúde, da propriedade e do meio ambiente. 0 conceito reúne a manutenção estrutura e das operações em sua totalidade como, também, a preservação de valores constitucionalmente protegidos, especificando a vida, a propriedade e o meio ambiente. Nesse sentido, a Lei 12.334 , no seu capitulo sobre fundamentos e fiscalização afirma que a segurança de uma barragem influi diretamente na sua sustentabilidade e no alcance de seus potenciais efeitos sociais e ambientais. A segurança de uma barragem deve ser considerada nas suas fases de planejamento, projeto, construção, primeiro enchimento e primeiro vertimento, operação, desativação e de usos futuros (art. 4a, I). A lei desce a detalhes ao apontar o tempo ou a oportunidade de ser feita a análise da segurança de uma barragem, não deixando aos órgãos fiscalizadores (art. 16) e ao empreendedor (art. 17) 
discricionariedade em deixar de efetuar essa fiscalização.

Como se observa, a Lei de Segurança de Barragens, no seu capítulo sobre fundamentos e fiscalização, afirma que a segurança de uma barragem influi diretamente na sua sustentabilidade e no alcance de seus potenciais efeitos sociais e ambientais, o que vai diretamente de encontro com os preceitos dos ODS.

No tocante à fiscalização, Machado (2013) ainda ensina que a Lei de segurança de barragens, constituiu uma fulgente relação dos órgãos públicos com os empreendedores, dependendo da finalidade da barragem e que os órgãos públicos competentes deverão atuar não só com probidade, mas com eficiência, para não ficarem extremamente dependentes em sua ação fiscalizadora dos dados colhidos somente pelo próprio empreendedor.

O mesmo autor, também salienta que a cultura da segurança é um fator essencial que deve ser incentivado, porém, assevera ser incomum e causa perplexidade dar-se tanto poder ao empreendedor de se autofiscalizar, pois e ele que vai realizar as inspeções de segurança e elaborar as revisões periódicas de segurança (art. 17, VIII e IX). Assim, as partes da lei que dizem que os órgãos públicos indicarão comportamentos do empreendedor cairão no vazio, o que contraria frontalmente a obrigação constitucional do Poder Público de controlar o risco (art. 225, § 10. V. da CF). (MACHADO, 2013).

Além disso, é certo que no Brasil, como já explanado anteriormente, existem legislações específicas como o Decreto Federal no 9.406/2018 (BRASIL, 2018), que busca conferir certa segurança, dinamismo e modernidade a um dos setores mais relevantes da economia nacional, já que o regulamento até então vigente datava de 1968 e, após diversos governos tentaram atualizá-lo, sem sucesso, o novo regulamento, agora contém novidades que buscam satisfazer parte das principais reivindicações do setor. Destacam-se, como principais novidades, o endurecimento de regras ambientais com a inclusão expressa da obrigação de fechamento de mina, e recuperação de áreas degradadas pelos mineradores; a mudança da contagem de prazo de pesquisa mineral e sua prorrogação em casos de dificuldades na obtenção de licenciamento ambiental ou acesso às respectivas áreas; a outorga de concessão de lavra como garantia para obtenção de financiamentos; o incentivo ao aproveitamento econômico de rejeitos e resíduos de mineração; e a sistematização do leilão eletrônico para a disponibilização de áreas que sofreram extinção de direitos minerários anteriormente válidos. (, YOSHIKAWA; CRIVELIN; JARDIM, 2019).

$O$ referido decreto demonstra também a determinação da nova agência de atrair para sua esfera a fiscalização e regulação de temática primordialmente ambiental, uma vez que lista elementos que poderão compor o fechamento da mina, como a recuperação da área degradada, a desmobilização de instalações, a utilização futura da área e o monitoramento e acompanhamento de sistemas de disposição de rejeitos e estéreis. (PLANALTO, 2018).

Pois bem, curial salientar, que o tema de segurança e fiscalização de barragens, tomou maior proporção de atenção com os lamentáveis desastres ambientais ocorridos em Mariana e Brumadinho no Estado de Minas Gerais (MACHADO; MORONG; SILVA, 2018).

Logo após o rompimento da Barragem de Fundão, surgiram importantes iniciativas legislativas para rever tal regulamentação, e uma delas foi a criação da Comissão Temporária, Externa, na Câmara dos Deputados, destinada a monitorar e acompanhar os desdobramentos do desastre ambiental, ocorrido em Mariana e região. O recente acontecimento da barragem de Brumadinho motivou parlamentares a solicitar o desarquivamento de antigas proposições de lei da Câmara dos Deputados, e deu origem a novas. (CORREIA, 2019).

Pois bem, em que pese a relevância do tema sobre a fiscalização e de segurança de barragens, o Atlas que mapeou os ODS na mineração, foi omisso em relação aos referidos assuntos. Contudo, é certo que o tema da fiscalização está inserida no contexto geral dos ODS. A título de exemplificação, é salutar demonstrar que o Conselho Nacional de Saúde (CNS), elaborou a Recomendação no 013, de 12 de abril de 2019, considerando, entre outros pontos, que os Objetivos de Desenvolvimento Sustentável (ODS) da Organização das Nações Unidas (ONU), em especial o de no 03, enquadrase no aspecto de monitoramento e fiscalização de grandes empreendimentos e seus impactos.

O ODS no 03 indica o dever de assegurar uma vida saudável e promover o bem-estar para todos, em todas as idades. A referida 
recomendação ressalta que só será possível cumprir os compromissos assumidos, se houver engajamento por parte do Estado e das empresas em uma agenda forte e coordenada, entre as instituições responsáveis por processos de licenciamento ambiental, saúde e segurança em ambientes de trabalho, monitoramento e fiscalização de grandes empreendimentos e seus impactos. (CONSELHO NACIONAL DE SAÚDE, 2019)

Do mesmo modo, pode-se trazer à baila, ainda que por analogia, o papel a ser desempenhado pelas Entidades de Fiscalização Superior (EFS), em relação à agenda de desenvolvimento pós-2015, que assevera que as EFS terão uma relevante função na implementação de mecanismos de monitoramento dos Objetivos de Desenvolvimento Sustentável (ODS) em nível nacional. (TCU, 2016).

Isto posto, conclui-se que, no que se refere ao tema de fiscalização e segurança de barragens, como ponto relevante para a consecução do desenvolvimento sustentável na mineração, ainda falta muito para o Brasil, assim como o resto do mundo, atingir padrões condizentes aos especificados nos 17 objetivos de desenvolvimento sustentável. Contudo, diante dos desastres nacionais mencionados, não se pode negar que, ainda que por grande pressão social, as autoridades estão tentando adequar a legislação a fim de evitar-se que outros incidentes semelhantes ocorram, e que as responsabilidades sejam pontualmente especificadas, com as consequências legais pertinentes.

É certo ainda que, o tema da fiscalização está inserida no contexto geral dos ODS, eis que a falta de fiscalização adequada, poderá aumentar o risco de ocorrência de desastres naturais, o que, por si só, afronta objetivos do desenvolvimento sustentável, especialmente a vida saudável e bem estar, entre outros. Por isso, tal tema realmente é primordial e relevante para alicerçar os objetivos ambientais aqui estudados.

\section{CONCLUSÃO}

Da análise elaborada neste trabalho, conclui-se que os Objetivos de Desenvolvimento Sustentável (ODS) e as atividades de mineração brasileira se inter-relacionam, observando o grau de incentivo de sua efetiva implementação no território brasileiro e no mundo, bem como os aspectos relacionados à segurança de barragens e fiscalização.

Nesse sentido, a atividade minerária se mostra essencial tanto para a economia brasileira, quanto para a economia mundial. Todavia, do modo como realizado atualmente, gera diversos impactos negativos ao meio ambiente, como a poluição dos recursos hídricos, a diminuição da flora e fauna da região que está sendo praticada a extração e o assoreamento de rios. Além disso, origina impactos negativos também na esfera social ao redor, como as condições de trabalho desumanas de alguns trabalhadores a depender da região do país e a destruição e o litígio envolvendo terras indígenas, entre outros.

Destarte, mesmo mostrando ser economicamente vantajosa, é mister a necessidade da realização de estudos para fomentar a sustentabilidade desta atividade visando a compatibilizar dois interesses fundamentais: equilíbrio ambiental e desenvolvimento econômico.

Os Objetivos de Desenvolvimento Sustentável (ODS) oferecem oportunidades para as mineradoras, não só no quesito de suas próprias operações, como também para fora delas, na participação nas discussões em curso sobre sua atividade, e as consequências na população da região e com as partes interessadas para contribuir com 0 desenvolvimento sustentável.

Atualmente, tanto a ONU quanto os governos nacionais, buscam formas de avançar a agenda ODS com os setores de mineração, petróleo e gás. Esses esforços oferecerão oportunidades para as empresas compartilharem seu trabalho, e identificar novas oportunidades de colaboração e inovação. Tal diálogo assegurará que as melhores práticas sejam compartilhadas e que a contribuição potencial da indústria de mineração, possa ser totalmente aproveitada para o desenvolvimento sustentável.

Aliar sustentabilidade e a mineração se mostra muitas vezes uma tarefa difícil, pois não é segredo os diversos desastres ambientais causados por tal atividade, incluindo os recentemente ocorridos em Mariana e Brumadinho, demonstrando o quão urgente deve ser a mudança na forma como tal atividade é executada.

Entretanto, apesar de difícil a tarefa de tornar a mineração uma atividade sustentável, ela é possível. Os 17 Objetivos de 
Desenvolvimento Sustentável trazidos pela ONU estão, um por um, tornando a mineração e a sustentabilidade aliadas para um fim comum, sendo esse o desenvolvimento sustentável. Assim, até os objetivos aparentemente desconexos da mineração, tornam-se conectados quando analisados de forma mais concreta.

De outro lado, quando conta-se com um aparato de fiscalização por parte do Poder Público e órgãos responsáveis, a mineração passa a ser benéfica ao setor econômico e ao setor social brasileiro.

A atual legislação possui instrumentos específicos, contando com estudos direcionados ao Direito Minerário e uma rigorosa dinâmica destinada à emissão das licenças ambientais, e deixando a desejar no que tange às diretrizes de fiscalização, embora esteja evoluindo nesse sentido, como resposta à pressão social oriunda de desastres ambientais ocorridos recentemente.

Com efeito, o desenvolvimento sustentável deve estar unido a atividade de extração de minérios, devendo preservar o meio ambiente e também gerar o crescimento econômico, que traz consequentemente 0 desenvolvimento social, não restando dúvidas de que há sim caminhos para tanto.

Portanto, é patente a necessidade de interrelação e harmonia de medidas sustentáveis ligadas à mineração, alterando os métodos como as empresas consomem os recursos minerais, adotando práticas sustentáveis de forma a tornar a extração do minério uma atividade menos agressiva ao meio ambiente, utilizando-se de todas as tecnologias e estudos disponíveis para a minimização e compensação dos impactos gerados, investimentos econômicos para fins sociais e educacionais, sendo, portanto, os Objetivos de Desenvolvimento Sustentável (ODS) da ONU, balizas imprescindíveis para se chegar ao tão esperado desenvolvimento sustentável em âmbito das atividades minerárias no Brasil e no mundo.

\section{REFERÊNCIAS}

ANTUNES, P. B.. Direito Ambiental. 19. ed. São Paulo: Atlas, 2017.

BeltrÃo, A. F. G. Curso de Direito Ambiental. .2. ed. São Paulo: Método, 2014.

BRASIL. Decreto no 9.406, de 12 de junho de 2018. Brasília, DF: Presidência da República, [2018]. Disponível em:
http://www.planalto.gov.br/ccivil_03/_Ato20152018/2018/Decreto/D9406.htm. Acesso em: 05 ago. 2019.

BRASIL. Lei no 9.605, de 12 de fevereiro de 1998. Brasília, DF: Presidência da República, [1998]. Disponível em: http://www.planalto.gov.br/ccivil_03/leis/19605. htm. Acesso em: 29 jul. 2019.

BRASIL. Lei no 13.575, de 26 de dezembro de 2017. Brasília, DF: Presidência da República, [2017]. Disponível em: http://www.planalto.gov.br/ccivil_03/_Ato20152018/2017/Lei/L13575.htm. Acesso em: 30 jul. 2019.

BRASIL. Ministério da Saúde. Conselho Nacional de Saúde. Recomendação no 021, de 12 de abril de 2019. Brasília, DF, abril. 2019. Disponível em: http://conselho.saude.gov.br/recomendacoes/20 19/Reco021.pdf. Acesso em: 29 abr. 2019.

BRASIL. Ministério de Minas e Energia. Atlas: mapeando os objetivos de desenvolvimento sustentável na mineração. Brasília: MME, 2017. Disponível em: http://www.mme.gov.br/web/guest/paginainicial/outras-noticas/-

/asset_publisher/32hLrOzMKwWb/content/minis terio-de-minas-e-energia-e-pnud-lancamrelatorio-atlas-mapeando-os-objetivos-dedesenvolvimento-sustentavel-na-mineracao;jsessionid=4A4730D159C9F8DFACA2295674418 42A.srv155. Acesso em: 27 de abr. 2019

PNUD Brasil. Ministério de Minas e Energia e PNUD lançam relatório "Atlas: Mapeando os Objetivos de Desenvolvimento Sustentável na Mineração" Notícias, 23 ago. 2017. Disponível em:

http://www.br.undp.org/content/brazil/pt/home Lpresscenter/articles/2017/08/23/minist-rio-deminas-e-energia-e-pnud-lan-am-relat-rio-atlasmapeando-os-objetivos-de-desenvolvimentosustent-vel-na-minera-o-.html. Acesso em: 29 abr. 2019.

BRASIL. Tribunal de Contas da União. Preparando para os objetivos de desenvolvimento sustentável. Portal TCU. Disponível em: https://portal.tcu.gov.br/inovatcu/noticias/prepa rando-se-para-os-objetivos-de-desenvolvimentosustentavel.htm. Acesso em: 27 abr. 2019. 
COLUMBIA CENTER ON SUSTAINABLE INVESTMENT; SUSTAINABLE DEVELOPMENT SOLUTIONS NETWORK; WORLD ECONOMIC FORUM. Atlas: mapeando os objetivos de desenvolvimento sustentável na mineração. Genebra, 2017. Disponível em: www.br.undp.org/content/dam/brazil/docs/ publicacoes/atlas-mineracao-ods.pdf. Acesso em 29 abr. 2019.

CONFEDERAÇÃO NACIONAL DA INDÚSTRIA - CNI. Mineração e Economia Verde. Brasília, 2017. Disponível em: https://portaldamineracao.com.br/wpcontent/uploads/2017/10/sustentabilidade_ibra m_2017_web.pdf. Acesso em: 28 abr. 2019.

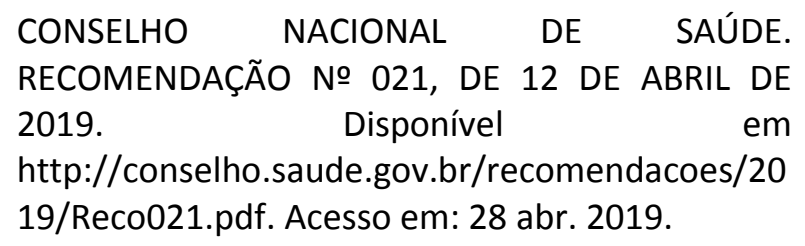

CROSS-SECTOR BIODIVERSITY INITIATIVE. A crosssector guide for implementing the Mitigation Hierarchy. 2015. Disponivel em: https://www.icmm.com/document/9460. Acesso em: 02 ago. 2019.

CUNHA, A. M. B. M.; GUEDES, G. B. Mineração e os objetivos de desenvolvimento sustentável: 0 desafio da diversificação econômica em Itabira (MG). Rio de Janeiro: CETEM/MCTIC, 2017. (Série Estudos e Documentos, 94).

Victor Athayde Silva

SILVA, V. A. . O novo regulamento do Código de Mineração e a atribuição da ANM em matéria de fiscalização ambiental. David \& Athayde, 11 maio $2018 . \quad$ Disponível em: http://www.da.adv.br/artigos/o-novoregulamento-do-codigo-de-mineracao-e-aatribuicao-da-anm-em-materia-de-fiscalizacaoambiental/657/. Aceso em: 03 ago. 2019.

ALMEIDA, C. M. et al. Estudo de caso - município Linhares - ES. 2019. Trabalho de conclusão (Especialização em desenvolvimento local e objetivos de desenvolvimento sustentável) -

ENAP, Brasília, 2019. Disponível em: https://repositorio.enap.gov.br/bitstream/1/416 8/1/Estudo\%20de\%20Caso\%20-\%20Linhares\%20\%20Grupo\%20I.pdf. Acesso em: 27 Jul 2019.

ENRíQUEZ, M. A. R. S.; DRUMMOND, J. A. Mineração e desenvolvimento sustentável - dimensões, critérios e propostas de instrumentos. p. 249-275. In: Tendências tecnológicas Brasil 2015: geociências e tecnologia mineral. Rio de Janeiro: CETEM/MCT. 2007.

CORREIA, C. O que o Congresso Nacional tem feito para evitar casos como de Mariana e Brumadinho?. Estadão, São Paulo, 26 fev. 2019. Disponível em: https://politica.estadao.com.br/blogs/legisativo/o-que-o-congresso-nacional-tem-feitopara-evitar-casos-como-de-mariana-ebrumadinho/. Acesso em: 25 abr. 2019.

ESTRATEGIA ODS. Como avançar nos ODS?. Disponível em: www.estrategiaods.org.br/o-quesao-os-ods/como-avancar-nos-ods. Acesso em: 25 abr. 2019.

GIL, A. C. Métodos e técnicas de pesquisa social. 6. ed. São Paulo: Atlas, 2008.

ICMM, 2006. Maximizing Value: Guidance on Implementing Materials Stewardship in the Minerals and Metals Value Chain. Disponível em: http://www.icmm.com/document/14. Acesso em: 2016.

ICMM, 2012. The role of mining in national economies. Disponível em: https://www.icmm.com/document/4440. Acesso em: 2016.

MACHADO, F. S.; MORONG, F. F.; SILVA, C. S; O papel da perícia ambiental no caso Mariana/MG. Colloquium Socialis, Presidente Prudente, v. 02, n. Especial 2, jul./dez., p.380-384 2018. https://doi.org/10.5747/cs.2018.v02.nesp2.s0308

MACHADO, P. A. L. Direito Ambiental Brasileiro. 21.ed. São Paulo: Malheiros Editores, 2013.

YOSHIKAWA, L. F.; CRIVELINI, Y.; JARDIM, P. H. Governo altera setor mineral por meio de decretos. Inteligência Jurídica Machado Meyer, 2019.Disponível em: https://www.machadomeyer.com.br/pt/decisoes /infra/governo-altera-setor-mineral-por-meio-dedecretos. Acesso em: 01 ago. 2019.

MORONG, F. F.; ALVES, L. N.O Acordo de Paris e sua Relação com a Sociedade Vulnerável: Breves considerações. In: COUTINHO, N. C. A.; AKIRA, M. $M$. (coords). Sociedades vulneráveis e proteção ambiental. Brasília, 2017. 
MORONG, F. F.; LIMA, N. L.2018. A Agenda 2030 e os 17 Objetivos de Desenvolvimento Sustentável e sua adoção em âmbito municipal local. Presidente Prudente/SP. UNOESTE. Programa Especial de Iniciação Científica - PEIC no 4795. Projeto de Pesquisa em andamento.

OLIVEIRA, M. G. S. A quem compete a responsabilidade pelo desastre do Distrito de Bento Rodrigues - MG. ECODEBATE. Disponível em:

https://www.ecodebate.com.br/2015/12/03/aquem-compete-a-responsabilidade-pelodesastre-do-distrito-de-bento-rodrigues-mgartigo-de-maria-galleno-de-souza-oliveira/. Acesso em: 31 jul. 2019.

PLATAFORMA AGENDA 2030. O que é a Agenda 2030?. Disponível em: http://www.agenda2030.com.br/. Acesso em: 09 abr. 2019.

PEREIRA, L. M. S. Aspectos gerais sobre a responsabilidade penal ambiental: breve correlação com caso de Mariana - MG. 2019. Trabalho de Conclusão de Curso (Graduação em Direito) - Universidade do Oeste Paulista UNOESTE, Presidente Prudente, 2019.

ROCHA, L. L.; LACERDA, C. A. M. Comentários ao Código de Mineração do Brasil. 1. ed. Rio de Janeiro: Forense, 1983.

SIRVINKAS, L. P. Manual de Direito Ambiental. 16. ed. São Paulo: Saraiva, 2018.

THE CITIES ALLIANCE, 2008. Slum Upgrading Up Close: Experiences of Six Cities. Disponível em: http://www.citiesalliance.org/sites/citiesalliance. org/files/su-up-close_0.pdf. Acesso em: 2016.

UNITED NATIONS, Sustainable Development Goals: Goal 2, 3, 5, 6, 8-17. 2016.Disponível em: http://www.un.org/sustainabledevelopment/hun ger/. Acesso em: 2016.

Goal 2: Zero Hunger 